whenever new scientific evidence can be brought to bear - will be presented to the European Parliament for inspection next month, and adopted by member states later this year. Already, many health-food companies, wary of possible litigation, have toned down their marketing claims.

The regulations, drafted by the European Commission and adopted by the EU in 2007, are intended to put an end to the free ride that the food and food-supplement industries have enjoyed until now. Companies will no longer be able to market their products with unproven promises that consumers will be healthier, slimmer or have happier lives. Even the words 'probiotic' and 'antioxidant' will disappear from food and foodsupplement labels in the absence of confirmed specific health benefits.

To implement the regulations, the EFSA - whose role is to supply scientific advice in support of EU policies - set about drawing up a register of permitted health claims for food ingredients, asking its expert committees to recommend for inclusion only those for which the claims have been unambiguously proven in healthy populations.

Of the 2,927 consolidated health claims for different ingredients examined by the EFSA, only 241 passed muster. A second chance was given to 91 of the non-approved claims, 74 of which related to microorganisms - pre- and probiotics. But the EFSA rejected all of the resubmitted dossiers except two: prunes for normal bowel function and the polysaccharide $\alpha$-cyclodextrin, a soluble dietary fibre, for limiting the rise in blood glucose after a meal.

The high rejection rate dismayed sections of the multibillion-euro health-food industry, which has lobbied fiercely against this legislation with disingenuous arguments that it inappropriately applies pharmaceutical standards to foods. In fact, it is the industry that has tried to make pharmaceutical-level claims for its products while bypassing medical-registration procedures and costly quality control.

But there is an elephant in the room: botanicals. Around 2,000 health claims for plant-based foods are on hold at the ESFA as manufacturers plead for special treatment. The manufacturers refer to the 2001 EU medicines directive which allowed traditional herbal medicines a simplified registration procedure not requiring rigorous proof of efficacy. The EU health commissioner must decide whether plant-based products marketed as health-promoting foods should be treated with similar leniency, but the decision has been shamefully delayed. The new commissioner, Tonio Borg, has been in office

"Already, many health-food companies, wary of possible litigation, have toned down their marketing claims." for only a few weeks, but he needs to bring clarity quickly — and to firmly reject moves to weaken requirements for scientific evidence.

The European Court of Justice may yet force a decision on the commission if it continues to prevaricate. The court is currently hearing three cases of unfair competition from manufacturers stopped from making claims on nonbotanical food and food supplements. Yogurt manufacturers, for example, do not consider it fair that botanicals can continue to be marketed with unproven claims of improving immune defences when they are no longer allowed to do so.

Faced with the new legislation, the yogurt industry has in fact buckled down to generate the scientific evidence that the commission wants. Manufacturers have joined forces to produce a meta-analysis of published evidence on some probiotic strains to try to get at least some claims onto the permitted list before it circulates to parliament. And they are also launching double-blinded clinical studies to prove that certain microbial strains have particular effects on health. That is an expensive exercise, but it is the price that must be paid by those who want to stay in the game.

\section{Realities of risk}

\section{We should focus on dangers that we can control, and particularly on those of our own creation.}

W hen policy-makers consider global risks, they tend to extrapolate from headlines. Troubles in the eurozone could spiral out of control, conflict in Syria could spark wider unrest, the H5N1 bird-flu virus could mutate and spread from person to person in a global pandemic. Those dangers and many others are clear and present; society is well-advised to prepare for them, and takes good advice on how to do so. The World Economic Forum (WEF), for one, publishes an annual risk-assessment report.

There is, however, another category of risk: the unheralded dangers that sneak up on us. Many are the unforeseen consequences of progress, of humanity's scientific and technological quests. For its 2013 report, the WEF asked the editors and journalists of Nature to identify five of the most disruptive of these risks, dubbed ' $\mathrm{X}$ factors'.

Neuroscientists, for instance, are avidly pursuing drugs and devices that could deliver real cognitive enhancement - not just sharpening our alertness and ability to focus, as certain drugs already do, but upping our intellectual firepower. From students to business executives, the demand for such drugs would be huge - and so would the potential for an $\mathrm{X}$ factor to strike. Few drugs affect just a single target. The neurotransmitter systems important to cognition also serve other functions, raising the spectre of serious side effects: for example, a drug that boosts memory might also make the user more prone to impulsive behaviour. And then there are the ethical conundrums: should the market decide who gets the benefits of these drugs and who does not? Should they be banned, to level the playing field - or subsidized, for the same reason?

Climatologists have more mixed feelings about schemes for geoengineering - deliberately altering the climate system to combat the effects of rising greenhouse-gas emissions. In one scenario, highflying jets or balloons would release a haze of sulphate particles into the stratosphere, dimming the Sun's rays and cooling the planet. Fearful that geoengineering could affect the climate system in unexpected ways, researchers have deliberated and studied it, and so far proposed only the most cautious of experiments. A second X factor looms here: geoengineering is simple and cheap enough that a rogue nation, or even a company, could deploy it on a large scale before its risks are well understood, perhaps triggering a widespread climatic crisis.

The other X factors that Nature staff identified are no less dramatic: the societal burden of the millions of people who, thanks to progress against killer diseases, will join the ranks of the disabled and those with dementia; catastrophic climate feedback such as the collapse of an ice sheet; and the possible social consequences of contact with alien life (although this is perhaps more $\mathrm{X}$-files than $\mathrm{X}$ factor).

In this week's issue, Nature also takes up related topics. A World View on page 135 offers psychological insight into 'digital wildfires' (a danger explored in Global Risks 2013). These are a much more certain danger than the $\mathrm{X}$ factors - in fact, they are a regular feature of the Internet, flaring up practically by the minute as rumours or personal attacks race through cyberspace. Meanwhile, a Comment on page 157 examines the shortcomings of efforts to forecast state changes such as the collapse of ecosystems or the outbreak of epidemics.

Finally, a Feature on page 154 offers the liberating perspective that some of the very worst things that could happen - catastrophes that could devastate the biosphere, and human society with it - are out of our hands. These strokes of cosmic bad luck, among them supervolcanoes, apocalyptic tsunamis driven by undersea landslides, and $\rightarrow$ NATURE.COM To comment online, click on Editorials at: go.nature.com/xhunqv mega solar flares, have all happened in the geological past and are sure to strike again someday. But in many cases there is little we can do to prepare or stave them off - and so there is no point in worrying. 